\title{
Análise de Interações Familiares: Um Estudo de Caso
}

\author{
Ana Rita Coutinho Xavier Naves ${ }^{2}$ \\ Laércia Abreu Vasconcelos \\ Universidade de Brasília
}

\begin{abstract}
RESUMO - Este trabalho analisou as interações de uma família, em um contexto de laboratório, a partir de entrevistas com os pais e da participação dos membros familiares em tarefas análogas às do cotidiano - Lanche, Cartaz, Brincadeira e Organização da Sala, em um delineamento ABACA. A condição A correspondeu à linha de base. A variável independente foi um texto escrito, o qual descrevia comportamentos de uma família tradicional (Condição B) e de uma família contemporânea (Condição C). A partir da categorização dos comportamentos dos participantes e do registro de intervalo parcial, observou-se que as interações familiares diferiram mais entre as tarefas, independentemente da condição, do que entre linha de base e condição experimental. Os resultados indicaram que os comportamentos dos participantes se assemelharam àqueles observados no ambiente natural. Palavras-chave: contingências de reforçamento, valores, família
\end{abstract}

\section{Analysis of Family Interactions: A Case Study}

\begin{abstract}
The current study analyzed the interactions of one family, in a laboratory context, by means of interviews with the parents and of family members participation in tasks similar to those in everyday life - Lunch, Poster, Play and Organization of the Room. An ABACA design was employed. Condition A was baseline. The independent variable was a written text describing behaviors of a traditional family (Condition B) and of a contemporary family (Condition C). Based on the categorization of all participants interactions and the partial interval recording, it was observed that family interactions differed more among the tasks, independent of the condition, than between the baseline and experimental conditions. The results indicated that the behavior of the participants were similar to those observed in the natural environment.
\end{abstract}

Keywords: contingencies of reinforcement, values, family

A família está presente em todos os grupos sociais e introduz o indivíduo nas práticas culturais que regulam a vida em sociedade. "Entre as três instituições mais antigas da sociedade estão a família, a igreja e o estado" (Glenn, 1985, p. 18). A abordagem multidisciplinar da família tem recebido diversas contribuições advindas da Antropologia, Sociologia, Direito e Psicologia (e.g., Cohn, 2005; Polity, Setton, \& Colombo, 2004). Na Análise do Comportamento, a família deve ser considerada a partir de uma perspectiva histórica e dentro de um amplo contexto social que envolve a jurisdição, a política, a economia, a religião, a educação, as tecnologias, o sistema midiático e o processo de globalização com sua influência dinâmica. Assim, a unidade de análise é a interação entre os membros familiares, considerando também a história familiar e o amplo contexto social (Mattaini, 1999/2001). Sendo o comportamento do indivíduo o primeiro objeto de análise para a compreensão da dinâmica familiar, é necessário investigar as variáveis das quais o comportamento é função.

$\mathrm{O}$ comportamento humano está sujeito às leis das ciências naturais e, dessa forma, é também selecionado pelo ambiente, estando concomitantemente sob a ação de três níveis de variação e seleção: filogênese, ontogênese e cultura (Skinner, 1981). O nível filogenético se refere às mudanças nas características de populações de organismos que ocorrem ao longo do tempo biológico, ou seja, suas variações

1 Apoio: $\mathrm{CNPq}$

2 Endereço para correspondência: Universidade de Brasília, Departamento de Processos Psicológicos Básicos. Brasília, DF, CEP: 70.910-900 E-mail: anarita.naves@gmail.com genéticas. Nesse nível de variação e seleção, os genes são as unidades que variam e são replicadas, os quais selecionam as características fenotípicas. A partir do estudo da biologia do comportamento, observa-se a existência de repertórios filogeneticamente selecionados pela história ambiental do organismo, resultando em variações inter e intra-sujeitos (Tourinho \& Carvalho Neto, 2004).

Mais do que repertórios especificos, a filogênese seleciona a sensibilidade do organismo humano a certas formas de estimulação fisica ou social. (...) As sensibilidades especificas vêm a ser condições para que a aprendizagem ocorra e promova uma variabilidade comportamental, para além do que as topografias especificas possibilitam (Tourinho \& Carvalho Neto, 2004, p. 120).

Portanto, a seleção filogenética explica apenas a existência do corpo e do cérebro e prepara a espécie para um futuro que se assemelhe ao passado selecionador. Entretanto, a seleção filogenética não é capaz de explicar a variabilidade comportamental apresentada por diferentes indivíduos diante das constantes mudanças ambientais, já que o tempo de variação, seleção e replicação de uma determinada característica fenotípica envolve diferentes gerações de organismos (Glenn, 1991). O condicionamento operante, portanto, é o processo de variação e seleção que permite que o organismo apresente variabilidade comportamental (Skinner, 1953/1985, 1981). Por meio do condicionamento operante, novas respostas são fortalecidas por eventos por ela produzidos (Skinner, 1981). O nível ontogenético se refere, portanto, à história de vida 
de cada indivíduo da espécie desde o seu nascimento, sendo resultantes das interações que esse indivíduo estabelece com o seu meio em decorrência de aprendizagem (Skinner, 1953/1985). Nesse nível de variação e seleção, os padrões comportamentais são as unidades que variam e são replicadas, sendo selecionadas pelas consequências ambientais produzidas por esse padrão comportamental.

O terceiro nível de seleção por consequências do modelo causal proposto por Skinner é o cultural. A cultura pode ser definida como contingências de reforçamento social mantidas por um grupo. Ao contribuírem para a sobrevivência do grupo, as práticas culturais são selecionadas e transmitidas entre diferentes gerações (Skinner, 1984). Segundo Glenn (1991, 2010), a variação ocorre na interação entre os comportamentos dos indivíduos que participam da prática cultural e o ambiente. $O$ processo de seleção decorre das consequências culturais resultantes das contingências comportamentais entrelaçadas e do produto agregado.

Vale ressaltar que, no condicionamento operante, o comportamento pode ser analisado de momento a momento, ao contrário do que ocorre no nível filogenético e cultural. Além disso, a seleção por consequência nos três níveis de variação e seleção não ocorrem de forma independente. Segundo Skinner (1981), quando as consequências selecionadoras são as mesmas, o condicionamento operante e a seleção natural ocorrem juntos de forma redundante.

Observa-se que o paradigma evolucionista é utilizado para explicar a emergência não só de processos biológicos, mas também de processos comportamentais e culturais. No entanto, a evolução do comportamento de um organismo ao longo de sua vida ou a evolução das práticas culturais ao longo de diferentes gerações ainda não foi completamente compreendida pela ciência, apesar dos progressos científicos já alcançados. A evolução nos três níveis de variação e seleção ocorre devido às inúmeras trocas feitas entre o organismo e o ambiente, pois a reprodução, seja ela de novos indivíduos, de novos comportamentos ou de novas práticas culturais gera diferentes características que são selecionadas pelo ambiente no qual o indivíduo está inserido. Assim, para que a seleção ocorra, é necessário que as diferentes características geradas se enquadrem aos requisitos impostos pelo ambiente para que essas características permitam a sobrevivência e reprodução dos indivíduos (Glenn, 1991; Skinner, 1981).

\section{A Evolução da Família - uma instituição de controle social}

A família é muitas vezes identificada como uma instituição social, ou seja, como um sistema social no qual os indivíduos perpetuam seus valores para o bem-estar e sobrevivência do grupo (Champlim, 2002). Na Análise do Comportamento, podemos identificar a família como um sistema de múltiplos agentes, no qual um grupo de pessoas autônomas se comportam em conjunto de forma complexa, resultando em produtos que não seriam produzidos caso essas pessoas se comportassem individualmente. Tal definição diferencia a família de uma agência de controle, a qual, ao controlar conjuntos específicos de variáveis, são melhor organizadas que o grupo como um todo (Skinner, 1953/1985).
Alguns exemplos dessas agências de controle ou instituições são governo, religião e educação.

A estrutura familiar e as práticas educativas envolvendo as crianças são aspectos importantes a serem observados na evolução da família. Setton (2004), ao traçar a história da formação dos grupos familiares, mostra que a família surge durante o aparecimento das guerras, quando ocorre o rompimento dos grupos matrilineares. Entre os séculos XVI a XIX, não havia ainda uma separação entre os grupos familiar e social mais amplo - todos faziam parte de uma mesma comunidade. Apenas no século XX é que a estrutura familiar começou a se diferenciar do grupo social mais amplo e a família passou a ser definida por meio das relações de parentesco (Ariès, 1973/1981).

Diversas mudanças no grupo familiar se iniciaram após a Segunda Guerra Mundial. No Brasil do início do século $\mathrm{XX}$, o número de filhos era elevado, na relação entre adultos e crianças primavam-se pela obediência e pelo respeito aos mais velhos, a disciplina era feita pelos pais, os quais demonstravam afeto, e os avós eram membros familiares importantes para as crianças. O brincar se desenvolvia com brinquedos, em geral artesanais, e ainda, com brincadeiras que independiam da posse de brinquedos (Caldana, 1998). Entre as décadas de 1930 e 1980 houve uma maior limitação do espaço físico, as brincadeiras se tornaram solitárias, houve um maior número de objetos lúdicos disponibilizados pelas mães às crianças e a mídia televisiva começou a fazer parte da rotina familiar, difundindo valores. Diferentemente do início do século XX, ao final da década de 1990 houve um menor número de regras apresentadas às crianças e maior permissividade por parte dos pais. As crianças foram inseridas em um maior número de atividades extraescolares ao longo do dia, além de serem expostas cada vez mais ao universo midiático, especialmente à mídia de tela (Biasoli-Alves, 1997). Observam-se também outros fatores de influência na evolução da família contemporânea, tais como: aumento na frequência de divórcios, que conduziu a novas configurações familiares; a diminuição da taxa de natalidade; a inserção da mulher nas universidades e em atividades profissionais fora do ambiente doméstico; e a maior tendência de relações sexuais antes e fora do casamento (Turkenicz, 2006). É importante destacar que as mudanças na estrutura familiar brasileira e na sua função dentro da sociedade foram seguidas pela criação de três grandes conjuntos de leis: a Lei do Divórcio de 1977, o Estatuto da Criança e do Adolescente, criado em 1990, e o novo Código Civil Brasileiro de 2002.

$\mathrm{Na}$ análise do grupo familiar, é possível identificar dois núcleos familiares - a família nuclear, composta pelo casal, com a presença ou não de filhos, e a família ampliada, formada pelos membros familiares citados no primeiro núcleo e por outros indivíduos biologicamente associados ao pai ou à mãe, como avós, tios, sobrinhos e primos (Dias, 2006). Além disso, como decorrência das grandes modificações nos valores e constituição da família brasileira, observa-se a coexistência de dois modelos, tradicional e moderno (este último será denominado, neste trabalho, de contemporâneo). No primeiro modelo, os membros são definidos a partir de sua posição hierárquica, na qual o pai ocupa uma posição de poder sobre os demais membros e, no segundo modelo, o pai e a mãe têm iguais direitos e deveres e todos os membros são 
importantes para o desenvolvimento da família. Nesta síntese, é importante que não se desconsidere a complexidade das mudanças na instituição familiar (Caldana, 1998).

O estudo das interações do grupo familiar e dos valores presentes em cada família pode ser uma importante fonte de informações acerca das mudanças sociais vivenciadas pela sociedade. Assim, o objetivo geral deste trabalho é observar as interações entre os membros de uma família brasileira. Entre os objetivos específicos estão: 1) Observar e descrever as interações dos membros familiares em diferentes atividades, análogas àquelas presentes em alta frequência no cotidiano de uma família, tais como: lanche, confecção de um cartaz como uma atividade acadêmica, brincadeira e organização do espaço no qual interagem; 2) Analisar as descrições ou avaliações que os membros familiares formulam para sua respectiva família após a apresentação de dois modelos familiares pertencentes a diferentes períodos históricos; 3 ) Analisar as interações dos membros familiares, considerando também os relatos sobre a família ampliada - os valores, as práticas educativas, as definições de pai, mãe e criança.

\section{Método}

\section{Participantes}

Para a realização desta pesquisa obteve-se aprovação no Comitê de Ética da Faculdade de Ciências da Saúde da Universidade de Brasília (Processo 026/2007). A família foi recrutada por meio da divulgação de cartazes afixados na Universidade de Brasília que solicitavam a participação de famílias neste estudo. A Família é composta por pai (Francisco ${ }^{3}$ - 35 anos), mãe (Virgínia - 43 anos) e dois filhos (Hélio - 12 anos e Antônio - 4 anos). Francisco e Virgínia são casados há 15 anos e, após o nascimento de Hélio, o casal adotou o segundo filho, Antônio.

\section{Local e Material}

A pesquisa foi conduzida em uma sala do Centro de Atendimento e Estudos Psicológicos da Universidade de Brasília (CAEP) com espelho unidirecional entre esta sala e a sala de observação, onde observadores treinados permaneceram durante o experimento. Na sala havia uma mesa com alimentos dispostos para um lanche, cadeiras, almofadas e duas caixas, uma amarela, com livros e brinquedos (e.g., fantoches, conjuntos de chá e jantar de plástico, carrinho, conjunto de casinha em madeira e blocos de madeira ou blocos do engenheiro), e uma preta, com estímulos acadêmicos (e.g., lápis de cor, tesoura, cola, revistas). Nas condições experimentais $\mathrm{B}$ e $\mathrm{C}$, que serão descritas a seguir, havia frases sobre os diferentes modelos de famílias afixados nas paredes da sala (cartazes com tamanho A3, 297 mm x 420 $\mathrm{mm}$, impressos em cores).

3 Os nomes foram modificados para preservar a identidade dos participantes.

\section{Procedimento}

O procedimento envolveu seis sessões, uma por semana, totalizando um mês e meio de coleta de dados. Somente os responsáveis compareceram à primeira sessão, na qual eles leram e assinaram o Termo de Consentimento Livre e Esclarecido, autorizando os demais membros familiares a participarem. Nessa primeira sessão, os pais, individualmente, responderam também a um questionário sobre a rotina familiar, sua história pessoal com a família de origem (pais e irmãos), hábitos de lazer e conceitos sobre família. A partir da segunda sessão, as crianças foram inseridas e todos os participantes foram submetidos a um delineamento experimental ABACA, conforme Tabela 1, em que A corresponde às sessões de Linha de Base. Nas Condições B e $\mathrm{C}$, os pais receberam informações, de forma oral e textual, sobre o modelo familiar tradicional, aquele difundido até metade do século XX, e o modelo familiar contemporâneo, respectivamente.

Condição A - Linha de Base. Essa condição foi implementada na segunda, quarta e sexta sessões. Em cada sessão, a família permaneceu por volta de $40 \mathrm{~min}$ na sala com alimentos, objetos acadêmicos e brinquedos. O tempo foi dividido entre as instruções dadas pela experimentadora e as quatro tarefas a serem feitas pela família. Assim, nos primeiros $10 \mathrm{~min}$, a família foi instruída a fazer um lanche com os alimentos presentes na sala. Nos 10 min seguintes, foi instruída a fazer uma atividade acadêmica com os filhos. Essa atividade consistia em fazer um cartaz sobre algum tema definido pela experimentadora que foi escolhido por sorteio dentre os seguintes temas: televisão, alimentação, sentimento, rotina familiar e família. Nos 10 min seguintes, os participantes foram instruídos a brincar entre si com os brinquedos disponibilizados na sala. E, por fim, nos últimos 5 min, a família deveria guardar os brinquedos e os outros objetos utilizados na sessão (ver Mendizabal, 2005). As tarefas Lanche, Cartaz, Brincadeira e Organização da Sala foram selecionadas, dentre as diversas tarefas realizadas por uma criança em sua rotina diária, por serem atividades que podem representar as interações entre os membros familiares no ambiente doméstico.

Condição B - Modelo de Família Tradicional. Essa condição ocorreu na terceira sessão. Inicialmente, a experimentadora leu, juntamente com a família participante, um texto que apresentava a organização familiar no período histórico de aproximadamente 1900 a 1950. Nesse modelo, a mulher é apresentada como mãe e cuidadora, responsável pelas tarefas domésticas, pela administração da casa, pelo cuidado dos filhos e do marido (Del Priore, 1993); o homem, como responsável por sustentar econômica e financeiramente a família, sendo uma figura de autoridade que se torna necessária para impor limites, transmitir valores e cultura (Setton, 2004); e a educação dos filhos, voltada para torná-los adultos bem-educados, contém muitos limites e pouco afeto (Andrade, 1998).

Após a leitura do texto, que demorava cerca de $5 \mathrm{~min}$, a experimentadora formulou questões sobre o modelo de família apresentado (papel do homem, da mulher e das crianças) com o objetivo de observar os relatos acerca das interações e dos valores presentes na família deste estudo. As questões 
Tabela 1. Ordem de exposição das condições experimentais para a família participante.

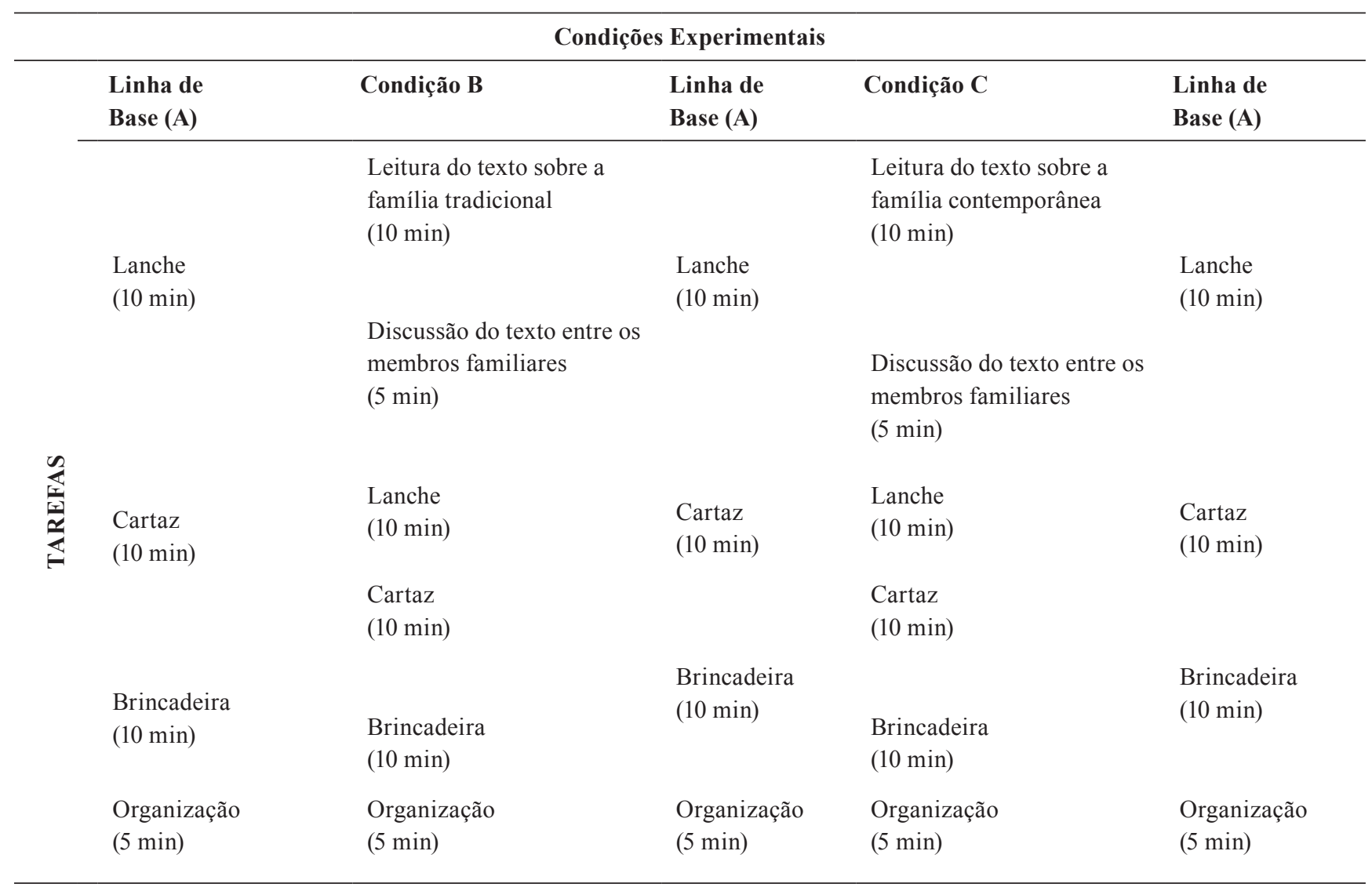

feitas aos participantes eram: De acordo com o texto, qual é o comportamento da mulher dentro da família? O que vocês pensam a respeito? Quais são os comportamentos do pai com relação à sua esposa e filhos? Como vocês vêem esses comportamentos? Como a criança deve ser tratada pelos pais? O que vocês pensam a respeito?

Posteriormente, foi solicitado aos participantes que discutissem o texto entre si, sem a presença da experimentadora, durante $5 \mathrm{~min}$. A seguir, os membros da família eram solicitados a realizar as mesmas tarefas da Linha de Base. No entanto, havia, dentro da sala, cartazes em folha A3 com alguns trechos do texto previamente apresentado: 1) A mulher é a mãe e a cuidadora, sendo responsável pela casa, pela família, pela manutenção do casamento e pela reprodução; 2) O pai impõe limites, transmite os valores e a cultura e a mãe demonstra carinho e amor; 3) O pai sustenta econômica e financeiramente sua família; e 4) A criança se desenvolve em direção ao objetivo de se tornar um adulto, ter comportamentos iguais aos do adulto com uma educação rígida, com muitos limites e pouco afeto. As condições B e C, esta última descrita a seguir, tiveram a duração de aproximadamente $1 \mathrm{~h}$.

Condição C-Modelo de Família Contemporânea. Essa condição ocorreu na quinta sessão, durante a qual a família recebeu um novo texto da experimentadora acerca dos valores familiares contemporâneos que se desenvolveram a partir do final do século XX, o qual era lido junto com os participantes. Nesse modelo, o homem e a mulher são co-responsáveis pelas atividades domésticas, pelo sustento financeiro da família e pelos cuidados com os filhos, que são educados com muito carinho, mas também com limites (Bastos, Alcântara, \& Ferreira-Santos, 2002; ECA, 1990; Turkenicz, 2006). Assim, cada membro da família possui direitos e deveres e são todos igualmente importantes para o desenvolvimento familiar e social.

Questões sobre o modelo apresentado, semelhantes àquelas utilizadas na Condição $\mathrm{B}$, foram feitas após a leitura do texto. Os participantes novamente foram requisitados a discutirem o texto por $5 \mathrm{~min}$, sem a presença da experimentadora, e foram expostos às mesmas atividades da Linha de Base e da Condição B - Lanche, Cartaz, Brincadeira e Organização da Sala. Os quatro cartazes dessa condição foram: 1) O pai e a mãe possuem iguais responsabilidades nos cuidados dos filhos e da casa; 2) A criança é um membro familiar que pode contribuir de forma importante dentro da família, expressando suas opiniões e sentimentos; 3) A educação dos filhos deve ser realizada com muito carinho, mas estabelecendo também limites, o que requer investimento de tempo e disposição dos pais, com diálogos frequentes; e 4) Pai e mãe têm vida familiar e vida profissional. Assim, as tarefas domésticas são compartilhadas.

Todas as sessões foram transcritas, sendo incluídas todas as interações dos membros familiares em cada sessão. Posteriormente, essas interações foram descritas em termos de contingências tríplices de reforçamento e punição, respeitando a sequência de comportamentos emitidos em cada sessão. A partir da formação dessas contingências tríplices, foram criadas categorias comportamentais como uma alternativa adicional de análise das interações (Sharpe \& Koperwas, 
Tabela 2. Definições operacionais das 11 categorias comportamentais emitidas pelos membros familiares nas sessões experimentais.

\section{Aprovação (AP)}

Desaprovação (DS)
Mostrar concordância após a emissão de um comportamento em uma determinada contingência. Ex.: "Minha mãe que é boa de colorir!"; sorrisos.

Mostrar discordância após a emissão de um comportamento em uma determinada contingência. Ex.: "Venha aqui, não vou falar mais não!"; "Pare de fazer isso com o tênis".

Descrever vocalmente comportamentos e/ou estímulos presentes em uma determinada situação. Ex.: "Ele gosta de biscoitos salgadinhos."; "Fiquei preocupada ao ver meu [da mãe] celular sem bateria e você [filho mais velho] não poder se comunicar comigo hoje de manhã".

Comentar ou perguntar de forma a mostrar uma crítica, discordância ou desvalorização do comportamento do outro, com a utilização de metáforas, brincadeiras e/ou sorrisos. Em geral, as perguntas já têm uma resposta, o falante já as conhece

Ironia (I) e solicita apenas uma confirmação. Ex.: "Se não é para comer a gente pára" [resposta do pai na tarefa de lanche diante da pergunta da mãe se ele não havia almoçado]; [na tarefa de brincadeira o pai mostra ao filho menor uma cama de boneca e a mãe pergunta] "Você gosta de brincar de boneca?".

Orientação (O)

Resposta à Solicitação (RS)

Verbalização Mínima de Afirmação (VMA)

Verbalização Mínima de Negação (VMN)
Guiar o comportamento do outro apresentando modelos verbais ou não-verbais. Ex.: "Você vai passar a canetinha pra ficar bem bonito."; "Pede direito".

Responder de forma não-vocal a uma solicitação de outro membro familiar. Ex.: O pai entrega um guardanapo para a mãe quando esta lhe solicita; o filho mais novo se levanta de cima do cartaz quando o irmão lhe pede.

Responder a uma pergunta concordando, com uma ou duas palavras ou com acenos positivos de cabeça. Ex.: "Sim"; "É"; "Estou".

Responder a uma pergunta discordando, com uma ou duas palavras ou com acenos negativos de cabeça. Ex.: "Não"; "Foi ruim".

Um membro familiar que não interage com os demais. Ex.: O filho mais velho brinca sozinho; o pai brinca sozinho; o pai lê; um membro familiar conversa consigo mesmo.

Emitir uma pergunta ou um pedido a outro membro familiar podendo envolver respostas não-vocais. Ex.: O filho pega um pacote de biscoito e olha para a mãe; "Vamos fazer um cartaz?"; "Coloque um copo de suco para mim?".

Dois ou mais membros familiares se unem para tentar resolver um problema. Ex.: A mãe ajuda o pai a abrir a caixa de suco.

\section{Resultados}

1983). Assim, uma determinada contingência poderia envolver diferentes categorias comportamentais emitidas por cada um dos membros familiares que dela participassem. Um total de 11 categorias comportamentais foram definidas e apresentadas na Tabela 2. É importante ressaltar que os comportamentos dos membros familiares foram categorizados a partir de sua topografia e função, observadas no contexto experimental. Além disso, não houve registros diferenciados para crianças e adultos participantes, ou para homem e mulher, tendo em vista que o objetivo da pesquisa era avaliar todas as interações familiares, independentemente de quem as emitisse.
Com o objetivo de descrever as interações dos membros familiares nas diferentes atividades propostas, foram desenvolvidas análises a partir das ocorrências das interações entre os membros familiares e da frequência das categorias comportamentais, além dos relatos obtidos em entrevistas e nas discussões sobre os diferentes modelos familiares apresentados. É importante ressaltar que, na medida de ocorrência, foram contabilizadas as interações estabelecidas por dois membros familiares entre si, independentemente de quem tenha iniciado a interação. Dois observadores registraram a ocorrência das interações (índice de concordância de $88 \%$, 
$\mathrm{SD}=9,74)$ e os comportamentos dos membros familiares de acordo com as categorias formuladas (índice de concordância de $71,6 \%, \mathrm{SD}=2,96)^{4}$, a partir das gravações das sessões experimentais.

Os relatos dos pais, durante a entrevista, e dos membros familiares, após a apresentação de dois modelos familiares, permitiram analisar as descrições ou avaliações que os membros familiares formulam para sua própria família. $\mathrm{Na}$ entrevista, Virgínia relatou que, em sua infância, seu pai, em geral, não corrigia os seus comportamentos inapropriados porque nunca estava em casa: com sua mãe era diferente, havia muito beliscão, surra e não-reconhecimento de comportamentos apropriados, os quais eram considerados um dever. Para Francisco, sua infância foi excelente, com acompanhamento total da mãe. $\mathrm{O}$ pai não participava porque viajava muito como caminhoneiro, permanecendo pouco tempo em casa. Francisco e Virgínia relataram que tentam não repetir o acompanhamento que receberam de seus pais na infância, buscando ser mais afetivos e participativos na educação de suas próprias crianças. No entanto, ambos disseram que, ao corrigirem um comportamento inapropriado dos filhos, são rígidos e autoritários, mas quando estes emitem um comportamento apropriado, os elogiam.

De acordo com as discussões sobre os dois modelos de família foi possível verificar que a família se avaliou como um exemplo do modelo de família tradicional. Segundo Virgínia, a única diferença entre sua família e o modelo de família tradicional apresentado é que sua função de mãe envolve a execução de todas as atividades domésticas e também as atividades de trabalho fora de casa. Em sua avaliação, o homem se dedica muito à área profissional, argumentando que deve manter financeiramente a família. Francisco relatou que tenta participar da educação dos filhos na hora do almoço, ao que Virgínia contestou dizendo que ele somente participa porque ela cobra. A esposa relatou que Francisco se irrita com os problemas domésticos, prefere mudar de assunto ou diz estar com sono. Hélio concordou com a mãe dizendo que o pai está sempre no trabalho e é ele quem determina qual é o castigo a ser dado, enquanto a mãe cuida das tarefas domésticas.

A Figura 1 apresenta o percentual de ocorrência das interações dos membros da família nas quatro tarefas - Lanche, Cartaz, Brincadeira e Organização da Sala - nas cinco sessões experimentais - Linha de Base 1 (LB1), Condição B (CB com a apresentação do modelo de família tradicional), Linha de Base 2 (LB2), Condição C (CC com a apresentação do modelo de família contemporânea) e Linha de Base 3 (LB3). Os intervalos parciais de ocorrência de interações (Bailey \& Burch, 2002) envolveram a duração total de cada tarefa, as quais foram divididas em intervalos de $15 \mathrm{~s}$, totalizando 40 possíveis intervalos de registro. Ou seja, a cada $15 \mathrm{~s}$ era registrado se um determinado membro familiar interagiu com o outro. Assim, por exemplo, se o pai interagisse durante toda a tarefa com Hélio, seria registrado $100 \%$ de ocorrência de interação; caso ele interagisse somente em 20 intervalos, seria registrado $50 \%$ de ocorrência de interação.

4 O índice de concordância foi mais baixo no registro das categorias comportamentais, pois o segundo observador categorizou erroneamente descrição (resposta vocal) como resposta à solicitação (não vocal).
Em geral, observa-se que as interações Mãe-Antônio (filho mais novo) tiveram as mais altas ocorrências nas diferentes tarefas, sendo seguidas, geralmente, pelas interações Mãe-Hélio (filho mais velho). As interações Mãe-Hélio ocorreram principalmente na tarefa do Cartaz, com ocorrências em torno de $60 \%$.

As interações do pai com o filho mais velho (Pai-Hélio) foram baixas em todas as tarefas nas cinco sessões analisadas. $\mathrm{Na}$ tarefa Lanche, o percentual de ocorrência ficou por volta de $25 \%$, o mais alto quando comparados os percentuais das quatro tarefas, com exceção da tarefa Cartaz na LB1, cujo percentual de ocorrência foi de $42,5 \%$. Já as ocorrências de interações entre o pai e o filho mais novo (Pai-Antônio) foram mais altas, principalmente durante a tarefa Brincadeira nas sessões LB1, CB e CC. Ao considerar as ocorrências de interações do pai na tarefa Brincadeira, na LB2, é importante citar que ele interagiu apenas em 14 intervalos com os demais membros familiares e nos demais intervalos brincou sozinho com os Blocos de Engenheiro. As poucas ocorrências de interação com Hélio foram devidas à insistência do filho em brincar com o pai, o qual não o incentivou em sua brincadeira.

As ocorrências de interações entre os irmãos (Hélio-Antônio) apresentaram muitas variações entre as tarefas e as sessões. Na LB1, os percentuais de ocorrências dessas interações se mantiveram em torno de $10 \%$ em todas as tarefas da sessão. Nas condições CB, LB2 e CC, os irmãos apresentaram percentual de 30\% nas tarefas Lanche, Brincadeira e Organização da Sala, mas este percentual foi menor na tarefa Cartaz, somente $10 \%$. Nas duas primeiras tarefas da LB3, o percentual de interação entre os irmãos ficou em torno de $15 \%$, aumentando para $45 \%$ nas duas tarefas seguintes. Por fim, a interação entre os pais apresentou uma média de $45 \%$ de ocorrência nas tarefas Lanche e Cartaz, independentemente da sessão analisada. Na tarefa Brincadeira, o percentual ficou por volta de $15 \%$ nas condições CB, LB2 e LB3, e por volta de $35 \%$ nas demais sessões.

A porcentagem das frequências das categorias comportamentais Aprovação (AP), Desaprovação (DS), Descrição (DE), Resposta à Solicitação (SP), Solicitação (SO) e Solução de Problemas (SP), para cada tarefa, é apresentada na Figura 2. Os valores apresentados foram obtidos a partir do total das frequências de cada categoria emitidas por todos os membros da família, em cada uma das tarefas, ao longo das cinco sessões experimentais. Posteriormente, foi calculado o percentual desse valor em relação à frequência total de categorias emitidas em cada tarefa. As porcentagens de cinco das 11 categorias comportamentais - Orientação, Verbalizações Mínimas de Afirmação e de Negação, Ironia e Sem Interação - se mantiveram abaixo de $5 \%$ nas quatro tarefas analisadas (Lanche, Cartaz, Brincadeira e Organização) e, por isso, seus valores não foram apresentados na Figura 2. Vale ressaltar que a categoria Ironia foi mais frequente na tarefa Lanche $(4,68 \%)$ e a categoria Sem Interação, na tarefa Brincadeira $(2,8 \%)$. A categoria Solução de Problema foi mais frequente nas tarefas Cartaz (6,9\%) e Organização da Sala (10,8\%), do que nas tarefas Lanche e Brincadeira, nas quais se manteve em torno de 1,5\%. Os percentuais das categorias Desaprovação e Aprovação foram baixos e semelhantes (7\% e 6\%, respectivamente), mas a categoria Aprovação diminuiu na tarefa Organização da Sala. A categoria Resposta à Solicitação 


\section{LB1}

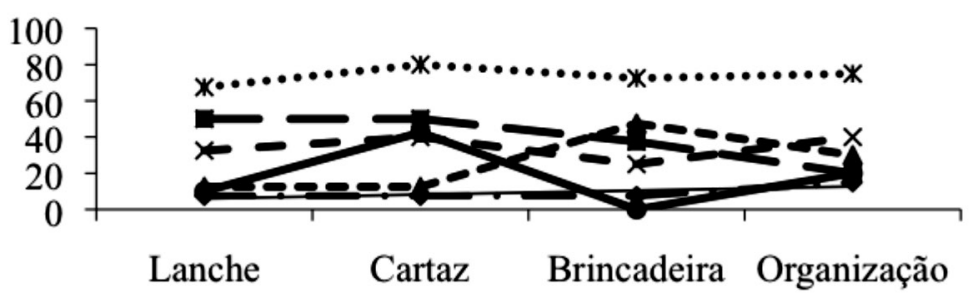

CB
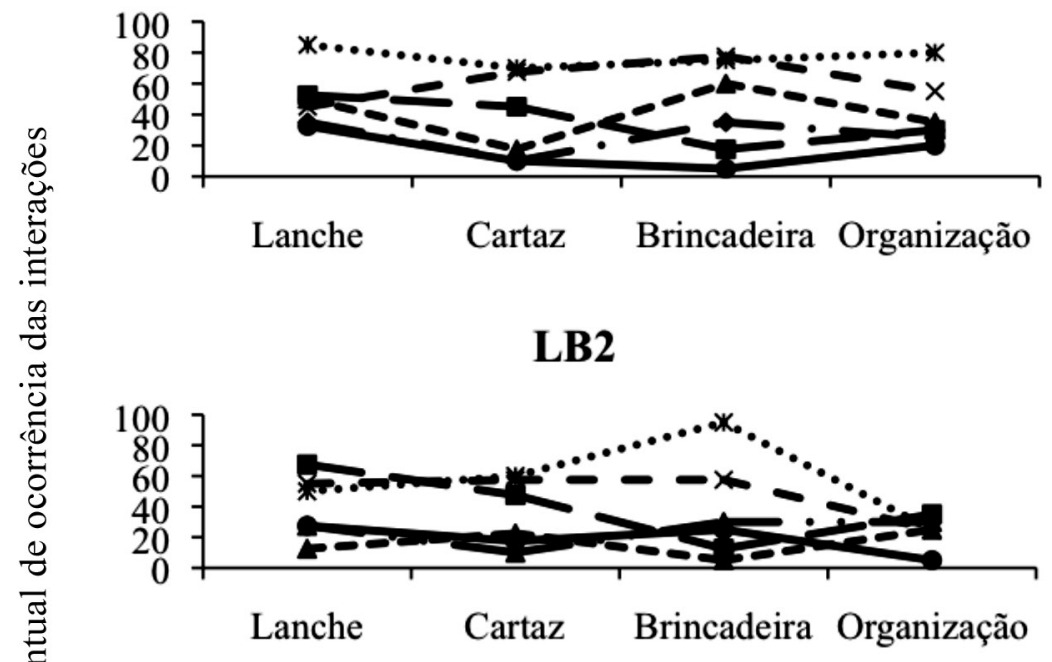

$\rightarrow$-Pai-Mãe

$\rightarrow$ Pai-Hélio

--A-Pai-Antônio

-※ Mãe-Helio

...*... Mãe-Antônio

$\rightarrow$ Hélio-Antônio

\section{CC}

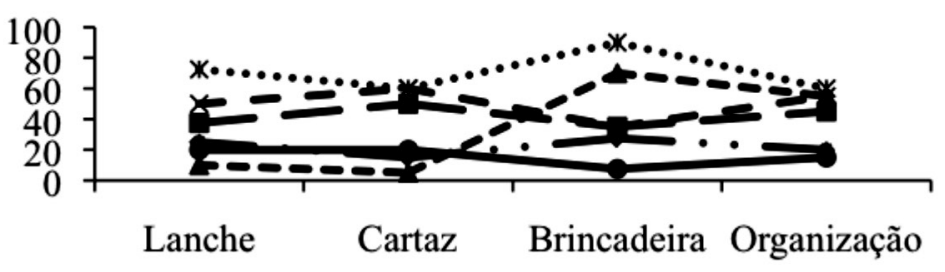

\section{LB3}

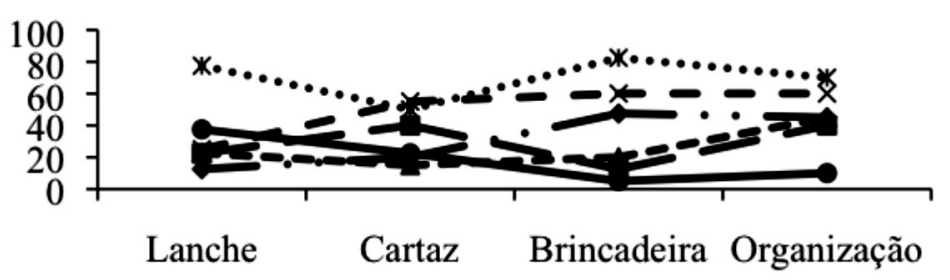

Tarefas

Figura 1. Percentual de ocorrência de interações entre os familiares em cada tarefa (Lanche, Cartaz, Brincadeira e Organização da Sala) durante a Condição A (LB1, LB2 e LB3 - Linhas de Base 1, 2 e 3), Condição B (CB - Família Tradicional) e Condição C (CC - Família Contemporânea). 


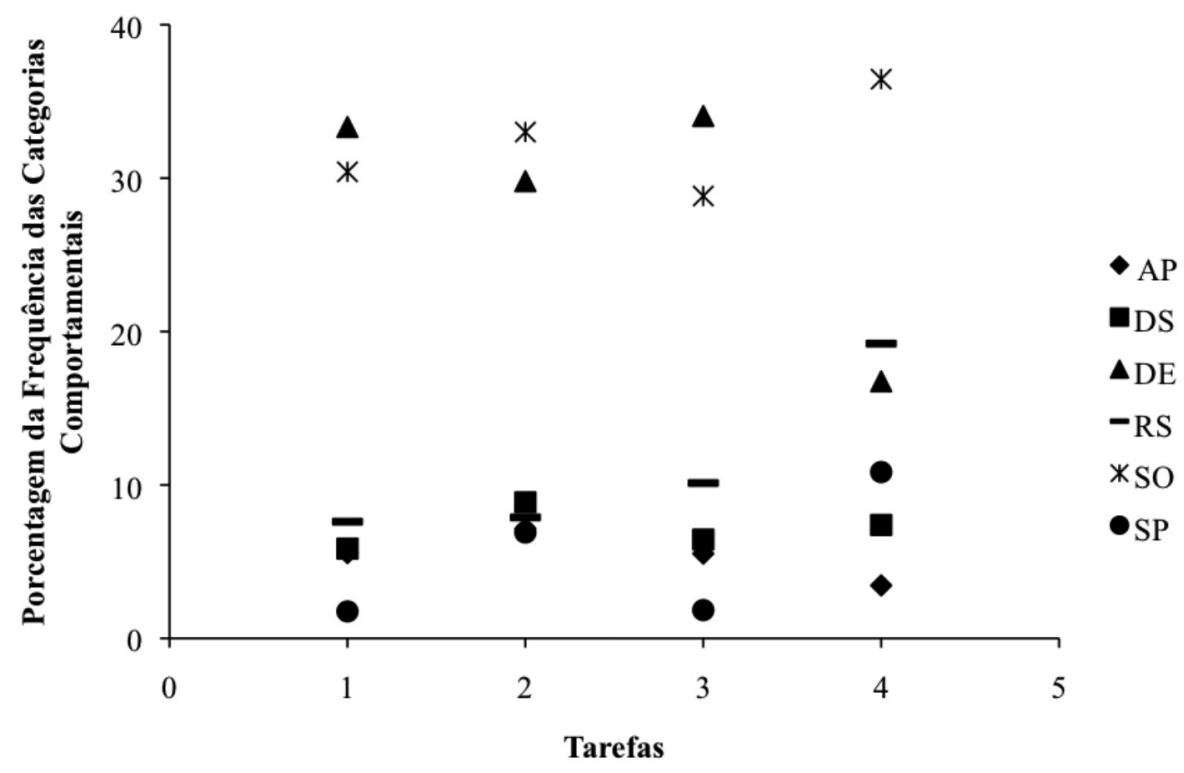

Figura 2. Porcentagem da frequência das categorias comportamentais (AP-Aprovação; DS-Desaprovação; DE-Descrição; RS-Resposta à Solicitação; SO-Solicitação; SP-Solução de Problemas) em cada tarefa (Lanche, Cartaz, Brincadeira e Organização da Sala) em todas as condições experimentais.

apresentou um percentual de $7 \%$ nas duas primeiras tarefas, $10 \%$ na tarefa Brincadeira e 19\% na tarefa Organização da Sala. As categorias comportamentais mais frequentes foram Solicitação (30\% a $36 \%$ ) e Descrição (16\% a $33 \%)$. Os valores dessas categorias foram aproximadamente constantes nas tarefas Lanche, Cartaz e Brincadeira, seguidos por um aumento na Solicitação $(36 \%)$ e diminuição na Descrição $(16 \%)$ na tarefa Organização da Sala.

\section{Discussão}

Este trabalho possibilitou analisar as interações entre os membros familiares em tarefas análogas àquelas presentes na rotina familiar, além dos dados relativos a um recorte da história da família participante, envolvendo especialmente partes da história de vida dos pais com sua família ampliada e a rotina familiar. A seguir serão apresentadas discussões acerca das interações entre os membros familiares no transcorrer das cinco sessões experimentais e as relações da família com o contexto social mais amplo, incluindo as mudanças sociais ocorridas no Brasil.

O primeiro objetivo deste trabalho foi investigar as interações dos membros de uma família em atividades similares àquelas presentes do cotidiano familiar. Foi possível observar que a presença de todos os membros de uma determinada família dentro do laboratório permite que se ampliem as análises sobre as relações sociais familiares. Além disso, as situações experimentais, baseadas em tarefas análogas presentes no dia a dia da família, podem ocasionar comportamentos semelhantes àqueles emitidos no ambiente natural. É importante destacar ainda que a situação de laboratório não parece ter sido aversiva para a família. Todos os familiares, em geral, participaram das tarefas propostas, não havendo faltas às sessões experimentais, tampouco atrasos.
A seguir serão apresentadas sínteses das interações em cada uma das tarefas programadas - Lanche, Cartaz, Brincadeira e Organização da Sala. Posteriormente, as interações presentes no núcleo familiar serão analisadas, envolvendo as famílias ampliadas do pai e da mãe participantes deste estudo. O Lanche foi a primeira tarefa análoga utilizada neste estudo. As práticas de alimentação têm um aspecto social fundamental na vida do indivíduo, pois desde o nascimento o alimento é apresentado na presença de outra pessoa (Heller, 2004). Em todas as idades a criança está em contato direto com seus pais ou cuidadores ao ser alimentada. $\mathrm{Na}$ amamentação, o bebê mantém contato com o corpo da mãe, e posteriormente, continuará a manter encontros com os pais durante as refeições, quando importantes decisões podem ser adotadas pela família. No presente estudo, as interações da mãe com os filhos tiveram algumas características que devem ser consideradas. A tarefa Lanche favoreceu as interações entre a mãe e o filho mais novo (Antônio) (ver Figura 1). Tais interações envolviam, em geral, o auxílio na tarefa, para evitar, por exemplo, que a criança derramasse o suco ou que sujasse a sala, enquanto as interações entre os pais e o filho mais velho (Hélio) envolveram diálogos sobre eventos ocorridos no cotidiano da família, nos últimos dias.

A tarefa do Cartaz favoreceu interações entre os membros mais velhos, principalmente a interação Mãe-Hélio (ver Figura 1). A influência do sistema escolar sobre a família pode ser observada ao considerar que quando foi solicitado aos pais que fizessem uma tarefa acadêmica com seus filhos, eles recorreram ao filho mais velho com domínio da leitura e escrita. Os vídeos das sessões mostram que as interações estabelecidas entre os pais e o filho mais novo, nessa atividade, não se referiam propriamente à tarefa, mas a outros estímulos presentes ou não no ambiente, tais como discussões acerca das figuras presentes nas revistas. É importante destacar que a categoria Desaprovação (DS) teve maior frequência nessa 
tarefa quando comparada às outras tarefas analisadas, como mostrado na Figura 2.

$\mathrm{Na}$ Análise do Comportamento, o desenvolvimento humano é definido como mudanças progressivas nas interações entre o comportamento de um indivíduo e o ambiente no qual ele está inserido desde o seu nascimento até a sua morte (Bijou, 1995), existindo comportamentos que possibilitam ao indivíduo contato com novos ambientes, sendo esses comportamentos chamado de cunhas comportamentais (do inglês behavioral cusps). O que define um determinado comportamento como uma cunha comportamental são as múltiplas oportunidades de interação que esse comportamento oferece ao indivíduo que se comporta. Quando uma cunha é adquirida, torna-se provável, ou mais fácil, a mudança de um conjunto de comportamentos importantes para o indivíduo (Rosales-Ruiz \& Baer, 1997). Por exemplo, o comportamento de andar pode ser considerado uma cunha comportamental, pois ao deixar de engatinhar e começar a andar, a criança passa a ter as mãos livres, o que lhe permite entrar em contato com novos estímulos, além de mudar seu campo de visão que antes era direcionado ao chão e passa a ser direcionado às pessoas e objetos de seu ambiente. $\mathrm{O}$ comportamento de brincar também pode ser definido como uma cunha comportamental ao permitir que novas interações do indivíduo com o meio emerjam a partir desse comportamento (De Rose \& Gil, 2003). A tarefa da Brincadeira favoreceu interações, entre os irmãos, que se mantiveram, de modo geral, baixas nas demais tarefas. Durante a tarefa da Brincadeira, os irmãos se uniram para brincar com os objetos da caixa, no entanto, o irmão mais velho se engajou em brincadeiras diferentes daquelas do irmão mais novo. $\mathrm{O}$ primeiro se interessou pelos jogos e pelos Blocos de Engenheiro e o segundo pelos móveis de madeira e pelos fantoches. Os fantoches foram estímulos que propiciaram interações que reproduziam padrões comportamentais da família, além de permitirem que um determinado membro familiar exercesse as funções de outro membro. Antônio, por exemplo, nomeou um dos fantoches de Família e brincou com ele em quatro sessões; na Linha de Base 3, ele assumiu a função de pai e castigou o fantoche que representava seu irmão por ter derrubado a mesa de brinquedo. Com relação às categorias comportamentais, ao contrário do que se pode esperar, a categoria Aprovação não se destacou como uma categoria frequente nas interações entre os irmãos durante a tarefa da Brincadeira,

Na tarefa Organização da Sala, o registro em vídeo possibilitou observar que todos os membros interagiram buscando alcançar o objetivo proposto no menor tempo possível. Assim, foi atribuída, por parte da família, a cada sessão experimental, uma área que cada membro familiar deveria organizar. Por exemplo, os filhos arrumavam a mesa de lanche enquanto os pais arrumavam os brinquedos. Nessa tarefa houve uma diminuição na categoria Descrição, pois a atividade não favorecia interações verbais vocais e houve um aumento nas categorias Solicitação, Resposta à Solicitação e Solução de Problemas. Os participantes pediam uns aos outros que organizassem determinados objetos, além de se unirem em pares para organizá-los (ver Figura 2).

Outro objetivo deste trabalho foi analisar as descrições formuladas pelos membros familiares a partir da entrevista com os pais e da apresentação dos textos acerca dos dois modelos de família (Tradicional e Contemporâneo) Assim, com base tanto nas interações observadas entre os membros da família, quanto na literatura pertinente, serão realizadas inferências sobre relações sociais, considerando a família em diferentes áreas de estudo como a Antropologia, Educação e Sociologia. A mãe relatou que apesar de trabalhar fora de casa, ainda assume o cuidado dos filhos e as tarefas domésticas, o que pode explicar as altas taxas de ocorrência das interações da mãe com os filhos. Entretanto, observa-se também a presença de comportamento verbal que sinaliza a valorização de uma mudança em busca de maior participação ou envolvimento da figura paterna no contexto doméstico. A mãe e o filho mais velho mostraram que o pai ainda é um membro familiar relativamente ausente na rotina doméstica, no cotidiano dos filhos. Diante de conflitos domésticos, ele se mostrava irritado e, em geral se esquivava de analisar ou buscar soluções.

Apesar do Estatuto da Criança e do Adolescente (1990) e o Código Civil (2002) regulamentarem que ambos os pais são responsáveis pela educação e sustento dos filhos, ainda se observa que essa responsabilidade não é compartilhada, ou seja, ao pai cabe o sustento financeiro e à mãe, a educação dos filhos (Del Priore, 1993; Scorzavafe \& Menezes-Filho, 2001; Sedlacek \& Santos, 1991). Estudos recentes mostram que a procriação ainda tem maior peso para a mulher. Ao considerar o impacto econômico após o nascimento dos filhos, Scorzafave (2004) mostra que quanto maior o número de filhos, menor é a participação da mulher no mercado de trabalho. Apesar das regulamentações legislativas e da insatisfação das mulheres ao cumprirem duplas jornadas de trabalho - dentro e fora de casa, sem a participação do marido na divisão das tarefas domésticas - essa prática cultural continua sendo mantida em muitas famílias. Segundo Skinner (1981), algumas práticas culturais se mantêm por longos períodos de tempo porque novas variações, ou seja, novas formas de comportamento, não apareceram ou aquelas que apareceram não foram selecionadas por contingências de reforçamento ou de sobrevivência do grupo.

Este trabalho teve como objetivo o estudo da família com foco sobre as interações entre os participantes e sobre a inserção da família em um contexto social mais amplo. No entanto, sugere-se algumas modificações em futuras replicações, tais como a realização de uma maior investigação acerca dos valores familiares (e.g., valores religiosos) que exercem controle sobre os padrões comportamentais de cada família. A análise de variáveis contextuais presentes nas famílias brasileiras contemporâneas também poderá ser ampliada em pesquisas adicionais com a participação de grupos familiares de outros estados da Federação, de diferentes níveis socioeconômicos, de organizações como o Movimento dos Trabalhadores Sem Terra e de populações indígenas.

\section{Referências}

Andrade, A. N. (1998). A criança na sociedade contemporânea: do 'ainda não' ao cidadão em exercício. Psicologia: Reflexão e Crítica, 11, 161-174. doi: 10.1590/S0102-79721998000100010 
Ariès, P. (1981). História social da criança e da família. (D. Flaksman, Trad.). Rio de Janeiro: LCT (Trabalho original publicado em 1973)

Bailey, J. S., \& Burch, M. R. (2002). Applied behavior analysis. California: Sage Publication.

Bastos, A. C. S., Alcântara, M. A. R., \& Ferreira-Santos, J. E. (2002). Novas famílias urbanas. In E. R. Lordelo, A. M. A. Carvalho, \& S. H. Koller (Eds.), Infância brasileira e contextos de desenvolvimento (pp. 97-133). São Paulo: Casa do Psicólogo.

Biasoli-Alves, Z. M. M. (1997). Famílias brasileiras do século XX: os valores e as práticas de educação da criança. Temas em Psicologia, 5(3), 33-49.

Bijou, S. W. (1995). Behavior analysis of child development. Reno: Context Press.

Caldana, R. H. L. (1998). A criança e sua educação na família no início do século: autoridade, limites e cotidiano. Temas em Psicologia, 6(2), 87-103.

Champlin, D. S. (2002). Antropo+Logia. São Paulo: ESETec.

Cohn, C. (2005). Antropologia da criança. Rio de Janeiro: Jorge Zahar Editor.

Del Priore, M. (1993). Ao sul do corpo. Rio de Janeiro: J. Olímpio e Brasília: Edunb.

De Rose, J. C. C., \& Gil, M. S. C. A. (2003). Para uma análise do brincar e de sua função educacional - a função educacional do brincar. In M. Z. S. Brandão, F. C. S. Conte, F. S. Brandão, Y. K. Ingberman, C. B. Moura, V. M. Silva, \& S. M. Olian (Eds.), Sobre comportamento e cognição, Vol. 11 (pp. 373-382). Santo André: ESETec.

Dias, M. L. (2006). Famílias \& terapeutas. Casamento, divórcio e parentesco. São Paulo: Vetor.

Glenn, S. S. (1985). Some reciprocal roles between Behavior Analysis and Institutional Economics in post-darwinian science. The Behavior Analyst, 8(1), 15-27.

Glenn, S. S. (1991). Contingencies and metacontingencies: Relations among behavioral, cultural and biological evolution. In P. A. Lamal (Ed.), Behavioral analysis of societies and cultural practices (pp. 39-73). New York: Hemisphere Publishing Corporation.

Glenn, S. S. (2010). Metacontingencies, selection and OBM: Comments on "Emergence and Metacontingency". Behavior and Social Issues, 19, 79-85.

Heller, D. C. L. (2004). Obesidade infantil. Manual de prevenção e tratamento. Santo André: ESETec.

Lei $n^{\circ} 6.515$ (1977, 26 de dezembro). Lei do divórcio. Retirado em 26 de outubro de 2007, de http://www.planalto.gov.br/ ccivil_03/Leis/L6515.htm

Lei n 8.069 (1990, 13 de julho). Estatuto da Criança e do Adolescente. Presidência da República. Retirado em 17 de setembro de 2006, de http://www.planalto.gov.br/ccivil_03/ leis/L8069.htm

Lei n ${ }^{\circ} 10.406$ (2002, 10 de janeiro). Código Civil. Presidência da República. Retirado em 20 de junho de 2007, de http://www. planalto.gov.br/CCIVIL/leis/2002/L10406.htm

Mattaini, M. A. (2001). Clinical intervention with families. Washington: Nasw Press (Trabalho original publicado em 1999)

Mendizabal, F. P. (2005). Efeitos da exposição a filmes sobre práticas educativas maternas. (Dissertação de Mestrado não publicada). Universidade de Brasília, Brasília.
Polity, E., Setton, M. Z., \& Colombo, S. F. (2004). Ainda existe a cadeira do papai? São Paulo: Vetor.

Rosales-Ruiz, J., \& Baer, D. M. (1997). Behavioral cusps: A developmental and pragmatic concept for Behavior Analysis. Journal of Applied Behavior Analysis, 30(3), 533-544.

Scorzafave, L. G. D. S. (2004). Caracterização da inserção feminina no mercado de trabalho e seus efeitos sobre a distribuição de renda. (Tese de Doutorado não publicada). Universidade de São Paulo, São Paulo.

Scorzafave, L. G., \& Menezes-Filho, N. A. (2001). Participação feminina no mercado de trabalho brasileiro: evolução e determinantes. Pesquisa e Planejamento Econômico, 31(3), 441-477.

Sedlacek, G., \& Santos, E. (1991). A mulher cônjuge no mercado de trabalho como estratégia de geração de renda familiar. Pesquisa e Planejamento Econômico, 21(3), 449-470.

Setton, M. Z. (2004). Uma visão histórico-antropológica sobre a paternidade. In E. Polity, M. Z. Setton, \& S. F. Colombo (Eds.), Ainda existe a cadeira do papai? Conversando sobre o lugar do pai na atualidade (pp. 45-57). São Paulo: Vetor.

Sharpe, T., \& Koperwas, J. (1983). Behavior and sequential analyses. California: Sage Publications.

Skinner, B. F. (1985). Ciência e comportamento humano (J. C. Todorov \& R. Azzi, Trads.). São Paulo: Martins Fontes (Trabalho original publicado em 1953)

Skinner, B. F. (1981). Selection by consequences. Science, 213, 501-504.

Skinner, B. F. (1984). The evolution of behavior. Journal of the Experimental Analysis of Behavior, 41(2), 217-221.

Tourinho, E. Z., \& Carvalho Neto, M. B. (2004). O conceito de estado inicial na explicação do comportamento humano: considerações de uma perspectiva analítico-comportamental. In M. L. S. Moura (Ed.), O bebê no século XXI e a psicologia em desenvolvimento (pp. 111-134). São Paulo: Casa do Psicólogo.

Turkenicz, A. (2006). Famílias ocidentais no século XX. In F. O. Portella \& I. S. Franceschini (Eds.), Família e aprendizagem - Uma relação necessária (pp. 11-36). Rio de Janeiro: Wak Editora.

Recebido em 30.12.2010

Primeira decisão editorial em 28.01.2013

Versão final em 15.05.2013

Aceito em 15.05.2013 